\title{
Physician assistant home visit program to reduce hospital readmissions
}

John P. Nabagiez, MD, Masood A. Shariff, MD, Muhammad A. Khan, MD, William J. Molloy, PA-C, and Joseph T. McGinn, Jr, MD

Objective: A physician assistant home care (PAHC) program providing house calls was initiated to decrease hospital readmission rates. We evaluated the 30-day readmission rates and diagnoses before and during PAHC to identify determinants of readmission and interventions to reduce readmissions.

Methods: Patients who underwent cardiac surgery were evaluated postoperatively for 13 months as pre-PAHC (control group) and 13 months with PAHC. Physician assistants made house calls on days 2 and 5 following hospital discharge for the PAHC group. Both groups were seen in the office postoperatively. We retrospectively reviewed the charts of 26 months of readmissions. Readmission rates for the control and PAHC groups were compared, as were the reasons for readmissions. Readmission diagnoses were categorized as infectious, cardiac, gastrointestinal, vascular, pulmonary, neurologic, and other. Also noted were the interventions made during the home visits.

Results: There were 361 patients (51\%) in the control group and 340 patients $(49 \%)$ in the PAHC group. Overall readmission rate for the control group was $16 \%$ (59 patients) and $12 \%$ (42 patients) for the PAHC group, a $25 \%$ reduction in the rate of readmissions $(P=.161)$. The rate of infection-related readmissions was reduced from $44 \%$ (26 patients) to $19 \%$ ( 8 patients) $(P=.010)$. Home interventions included adjustment of medications $(90 \%)$, ordering of imaging studies $(7 \%)$, and administering direct wound care $(2 \%)$.

Conclusions: The 30 -day readmission rate was reduced by $25 \%$ in patients receiving PAHC visits. The most common home intervention was medication adjustment, most commonly to diuretic agents, medications for hypoglycemia, and antibiotics. (J Thorac Cardiovasc Surg 2013;145:225-33)

The average length of stay for cardiac surgery patients has decreased over time, but their acuity and comorbiditites have increased, resulting in a high rate of readmission often requiring expensive procedures. $^{1-3}$ Many patients recovering from cardiac surgery are elderly; some live alone and may have little or no family support. ${ }^{4-6}$ Therefore the early postoperative period presents significant physical and emotional challenges. ${ }^{4,7}$ Hannan and colleagues ${ }^{1}$ found that in New York State the 5 most common 30-day readmission diagnoses following coronary artery bypass graft $(\mathrm{CABG})$ procedure were postoperative infection $(16.9 \%)$, heart failure $(12.8 \%)$, other complications of surgical and medical care $(9.8 \%)$, cardiac dysrhythmia $(6.3 \%)$, and angina $(4.7 \%)$.

\footnotetext{
From the Cardiothoracic Surgery Department, Staten Island University Hospital, Staten Island, New York.

Disclosures: Authors have nothing to disclose with regard to commercial support.

Read at the 38th Annual Meeting of The Western Thoracic Surgical Association, Maui, Hawaii, June 27-30, 2012.

Received for publication June 25, 2012; revisions received Sept 10, 2012; accepted for publication Sept 20, 2012.

Address for reprints: John P. Nabagiez, MD, Cardiothoracic Surgery Department, Staten Island University Hospital, 475 Seaview Ave, 3rd Floor Heart Tower, Staten Island, NY 10305 (E-mail: jnabagiez@ siuh.edu).

$0022-5223 / \$ 36.00$

Copyright (c) 2013 by The American Association for Thoracic Surgery http://dx.doi.org/10.1016/j.jtcvs.2012.09.047
}

A few studies assessing long-term follow-up of patients undergoing $\mathrm{CABG}$ procedure who received home intervention showed favorable outcomes. ${ }^{4,8-10}$ Lie and colleagues ${ }^{9}$ implemented a home-based intervention program that included two 1-hour visits by a trained nurse (with a master's degree) along with psychologic support and education. ${ }^{9}$ There is little documentation of physicians or physician assistants (PAs) making home visits. In the field of general surgery, Shapiro and colleagues ${ }^{11}$ measured if a surgeon's visit to a patient's home improved medical outcome and concluded that the physician's visit did not seem to influence outcome; however, it strengthened the patient-surgeon relationship. Our physician assistant home care (PAHC) program was implemented to provide house calls to patients recovering from cardiovascular surgery. The primary objective was to study the influence of a PAHC visit in reducing 30-day hospital readmissions following cardiac surgery. The secondary objectives were to compare the readmission diagnoses during the control and PAHC periods to assess the nature and utility of home-based interventions.

\section{MATERIALS AND METHODS}

All patients discharged to home following CABG procedure and/or valve repair or replacement and/or aneurysm repair, or other cardiac procedure from August 1, 2009, to September 30, 2011, at Staten Island University Hospital, a 714-bed tertiary care facility, were studied. The control group totaled 361 patients from August 2009 through August 2010, and 


\section{Abbreviations and Acronyms \\ $\mathrm{CABG}=$ coronary artery bypass graft \\ $\mathrm{PA}=$ physician assistant \\ PAHC $=$ physician assistant home care}

the PAHC group totaled 340 patients from September 2010 through September 2011. Patients who died before discharge or were discharged to nursing homes and rehabilitation facilities were excluded. Both groups were seen in the office on postdischarge weeks 2 and 4 . The control group was seen at home by standard visiting nurses without any specialty training or expertise in caring for cardiac surgery patients.

The PAHC group was analyzed on an intention-to-treat basis. Hospitalemployed cardiothoracic PAs conducted home visits on postdischarge days 2 and 5, with occasional variation due to patient availability and Sundays, on which no house calls were made. The same hospital-based PAs responsible for perioperative and intraoperative care were assigned to make house calls. During a house call, the PA performed a focused physical exam and reviewed the patient's medications. Adjustments were made to the patient's medications, and new medications were prescribed, as necessary. The surgical wounds were examined carefully and all patient concerns were addressed. Prescriptions were written for antibiotics, blood work, or imaging studies when indicated. Arrangements were made if the patient needed to be evaluated as an inpatient. All findings were documented on the PAHC visit form (see Appendix 1).

A registry database of the perioperative record, hospital records, and office and house call charts were reviewed. The database review was approved for research by the Staten Island University Hospital Institutional Review Board, which waived the requirement for informed consent on the condition that the subjects' identities were hidden before analytical procedures were performed.

Readmission diagnoses were grouped into 1 of 7 discrete categories: infectious, cardiac, gastrointestinal, vascular, pulmonary, neurologic, and other. Readmission rates were compared pre-PAHC and during the PAHC program, as were readmission diagnosis categories as a percent of total readmissions. Interventions made during house calls were examined and categorized. Data analysis was performed using SPSS 16.0 software (IBM Corp, Armonk, NY). Baseline characteristics were compared across groups using $\chi^{2}$, Fisher exact test, and $t$ tests, where appropriate. All tests were 2-tailed. Assuming a rate of refusal or exclusion of $10 \%$, a 2 -sided type I error rate of $5 \%$ and a power of $90 \%$, we calculated that a sample size of 740 patients was required to permit the detection of a $4 \%$ reduction in hospital readmission rate.

\section{RESULTS}

From August 2009 to September 2011, 1013 patients underwent cardiovascular surgery, $701(69 \%)$ of whom were discharged directly to their home. The control group, from August 2009 through August 2010, totaled 361 patients $(51 \%)$ and the PAHC group, from September 2010 through September 2011, totaled 340 patients (49\%) with a readmission rate of $16 \%$ (59 patients) and $12 \%$ (42 patients), respectively, a $25 \%$ reduction in the rate of hospital readmission $(P=.161)$. Baseline characteristics were comparable in both groups (Table 1). When comparing the number of patients readmitted by postoperative day, the difference between the control and the PAHC groups was most pronounced in the first 2 postoperative weeks (see Figure 1). Readmission categories, as a percent of total readmissions for the control group and the PAHC group, respectively, were: infectious, $44 \%$ and $19 \%$ $(P=.010)$; cardiac, $20 \%$ and $33 \%(P=.169)$; gastrointestinal, $10 \%$ and $19 \%(P=.248)$; vascular, $5 \%$ and $12 \%$ $(P=.445)$; pulmonary, $5 \%$ and $5 \%(P=1.000)$; neurologic, $5 \%$ and $2 \%(P=.639)$; and other, $10 \%$ and $10 \%$ $(P=1.000)$ (Figure 2). Infection-related readmissions, including wound infections (eg, sternal, lower extremity, and thoracoabdominal), pneumonia, and sepsis decreased from 26 patients $(44 \%)$ to 8 patients $(19 \%)(P=.010)$ (Table 2). The difference between the 2 groups for infectious readmissions was most pronounced during the first 2 weeks (see Figure 3). Table 3 lists the readmission categories as a percentage of each cohort.

Of 340 patients in the PAHC group, 65 (19\%) refused PAHC or failed to respond to requests to schedule a house call. Of 275 patients $(81 \%)$ who received home visits, 173 $(63 \%)$ were seen twice, $99(36 \%)$ were seen once, and 3 $(1 \%)$ were seen 3 times for a total of 454 visits, an average of 1.7 visits per patient. Of 42 patients readmitted during the PAHC period, $18(43 \%)$ received 2 visits, $13(31 \%)$ received 1 visit, and $11(26 \%)$ had no visits. A total of 454 house calls to 275 patients prompted a total of 122 interventions (Table 4).

Of 122 interventions documented during house calls, $110(90 \%)$ were medication related (Table 5), including 37 adjustments of diuretic medications (30\%), 15 changes to medications for hypoglycemia $(12 \%), 12$ prescriptions for antibiotics $(10 \%), 11$ prescriptions for stool softeners/ laxatives $(9 \%)$, and 9 adjustments to beta-blocker medications $(7 \%)$. The remainder of medication interventions were limited to 5 or fewer interventions ( $4 \%$ or less of total interventions) each and included antihypertensive medications, inhalers, analgesic medications, anticoagulant medications, aspirin, steroids, antiarrhythmia medications, antihistamine medications, antitussive medications, hypnotic agents, and proton pump inhibitors. Active wound care interventions were documented in 3 patients $(2 \%)$. Imaging studies were ordered for 9 patients: $3(2 \%)$ underwent a chest radiograph and $6(5 \%)$ underwent venous duplex exams (Table 2).

Our PAs are employed by the hospital and the home visits were incorporated into their daily schedule. Other than time spent away from the hospital, the only additional cost was travel expenses ( $\$ 0.55$ per mile) incurred while driving to patients' houses, which averaged about \$190/month for the volume encountered during the 13-month period.

\section{DISCUSSION}

Studies have revealed that social support improves patient health and compliance with recommended treatment and medications. ${ }^{6,12}$ Different methods have been described to aid patients undergoing $\mathrm{CABG}$ procedure in their recovery at home and improve functionality, adherence to therapy, and recognition of complications. ${ }^{6,8,11,13-15}$ Some 
TABLE 1. Baseline characteristics

\begin{tabular}{|c|c|c|c|}
\hline & $\begin{array}{l}\text { Control } \\
\text { group }\end{array}$ & $\begin{array}{l}\text { PAHC } \\
\text { group }\end{array}$ & $P$ value \\
\hline No. of patients & 361 & 340 & \\
\hline Age (mean y \pm SD) & $63.2 \pm 10.9$ & $62.8 \pm 10.6$ & 6929 \\
\hline Gender ( $\%$ male $)$ & $273(75.6)$ & $267(78.5)$ & .7746 \\
\hline \multicolumn{4}{|l|}{ Race } \\
\hline White & $318(88.0)$ & $289(84.4)$ & .7815 \\
\hline Other & 43 (11.9) & $53(15.5)$ & .2323 \\
\hline Current smoker & 99 (27.4) & $107(31.4)$ & .4281 \\
\hline Diabetes mellitus & $123(34.0)$ & $111(32.6)$ & .7629 \\
\hline Hypertension & $268(74.2$ & $283(83.2)$ & .3332 \\
\hline Dyslipidemia & $263(72.8)$ & $274(80.5)$ & .3900 \\
\hline Dialysis & $8(2.2)$ & $7(2.0)$ & 1.0000 \\
\hline Cerebrovascular accident & $15(4.1)$ & $9(2.6)$ & .3076 \\
\hline Chronic obstructive lung disease & $44(12.1)$ & $30(8.8)$ & .2214 \\
\hline Peripheral vascular disease & $29(8.0)$ & $25(7.3)$ & .7792 \\
\hline Previous myocardial infarction & $146(40.4)$ & $144(42.3)$ & .7800 \\
\hline Congestive heart failure & $51(14.1)$ & $48(14.1)$ & .9145 \\
\hline Arrhythmia & $37(10.2)$ & $39(11.4)$ & .6311 \\
\hline \multicolumn{4}{|l|}{ Procedures } \\
\hline CABG & $264(73.1)$ & $249(73.2)$ & 1.0000 \\
\hline Valve & $55(15.2)$ & $56(16.4)$ & .7594 \\
\hline Combined CABG + valve & $30(8.3)$ & $26(7.6)$ & .7829 \\
\hline $\begin{array}{l}\text { CABG }+ \text { valve }+ \text { other cardiac } \\
\text { procedures }\end{array}$ & $6(1.6)$ & $2(0.58)$ & .2887 \\
\hline Other cardiac procedures & $6(1.6)$ & $7(2.0)$ & .7838 \\
\hline
\end{tabular}

Data are $\mathrm{n}(\%)$, unless otherwise stated. PAHC, Physician assistant home care; $C A B G$, coronary artery bypass graft; $S D$, Standard Deviation.

institutions have tested if keeping in touch with postoperative patients at their home can provide guidance in recovery and glean helpful information. A telehealth device was used for a period of 12 weeks to assess symptoms, educate on recovery, and provide positive reinforcement. The intervention resulted in the group having fewer emergency room visits compared with the control group. ${ }^{15}$

There is evidence that communication with a patient at his or her home can help reduce rates of hospital readmission. ${ }^{15,16}$ Another study followed patients undergoing CABG procedure after home visits by nurses and found reduced anxiety levels among both patients and family members. ${ }^{7,17}$ Barnason and colleagues ${ }^{6}$ found that only 1 in 5 patient relatives who will be providing help at home feel adequately prepared for the patient's discharge from the hospital. Health care professionals can extend their expertise and technical knowledge to a patient's family to help in recovery.

The findings of this study suggest that house calls made by highly trained cardiothoracic PAs can reduce the hospital readmission rate following cardiac surgery. The critical feature of this initiative was using the same PAs responsible for perioperative and intraoperative care for the follow-up visits, rather than employing outpatient-based visiting nurses who exhibit a much lower threshold for emergency department referral. Retrospective analysis of a 26-month experience (13 months in a control group and 13 months in a PAHC group) yielded several interesting findings. The overall readmission rate was reduced from $16 \%$ to $12 \%$, a $25 \%$ reduction $(P=.161)$. By sorting all readmissions into 7 broad categories (infectious, cardiac, gastrointestinal, vascular, pulmonary, neurologic, and other) we discovered which readmission diagnoses were reduced by home visits. We believe the 2 most common categories of readmissions are, fortuitously, the most amenable to reduction by PAHC.

The most common readmission diagnosis was infection related, and this was the most dramatically reduced by PAHC from $44 \%$ to $19 \%$ of readmissions $(P=.010)$. It is self-evident that a home visit facilitates earlier diagnosis and treatment of a wound infection, but more surprising is the reduction in readmissions (from 8 patients to 1) for pneumonia and sepsis. Although the numbers are too small to demonstrate statistical significance, the difference is striking. It seems unlikely that these complications could be reduced by home visits, but it is possible that early diagnosis and treatment of wound infections or productive cough may indeed play a role in avoiding pneumonia and sepsis by preventing delayed presentation. A larger sample size would have produced a more definitive answer. The baseline characteristics of both groups were comparable and no other changes in infection control or antibiotic prophylaxis were initiated during the study period.

The second most common readmission diagnosis was cardiac related. Before PAHC we anticipated an overall reduction in readmissions for cardiac-related diagnoses. Our mixed results are difficult to explain other than by small sample size. Although congestive heart failure readmissions decreased from 4 to 0 , atrial fibrillation readmissions increased from 3 to 8 . Interestingly, diuretic medications were adjusted at 4 times the rate of beta-blockers (37 vs 9 , respectively) during home visits. Finally, the incidence of atrial fibrillation requiring readmission seemed by chance to be unusually low in the control group. It is understandable why other cardiac-related diagnoses such as myocardial infarction, pericardial effusion, syncope, and near-syncope were unaffected by home visits.

Gastrointestinal- and vascular-related readmission diagnoses are essentially unpreventable, and included upper and lower bleeding, cholecystitis, ileus, small bowel obstruction, incarcerated inguinal hernia, deep venous thrombosis, pulmonary embolism, and lower extremity acute arterial occlusion. Readmissions for neurologic diagnoses, including cerebrovascular accident, transient ischemic attack, and confusion are also largely unpreventable; however, anxiety may be a preventable condition. Although we had only 1 admission for anxiety in the control group, we had none during the PAHC period, and it is conceivable 


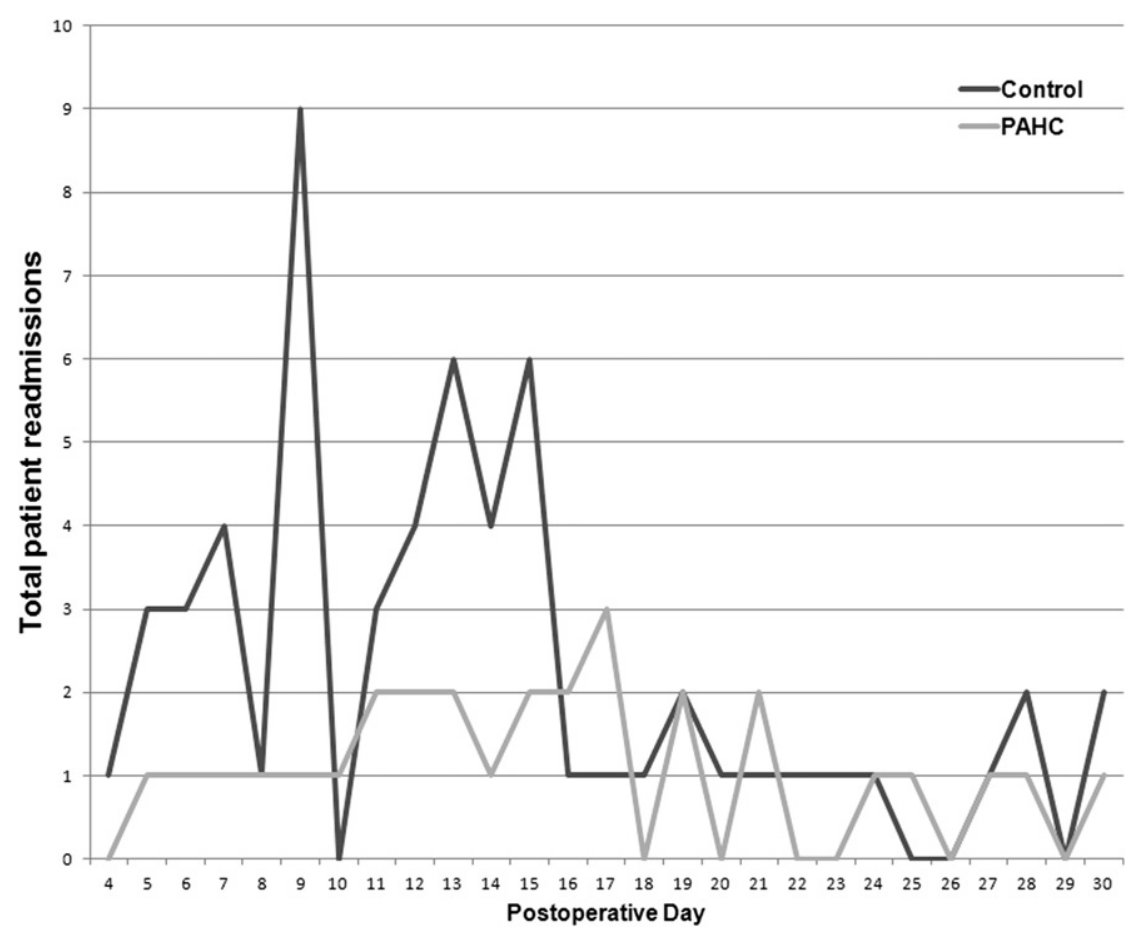

FIGURE 1. Thirty-day total hospital readmissions by postoperative day. $P A H C$, Physician assistant home care.

that reassurance by a PA with or without prescription of an anxiolytic drug may have played a role.

Pulmonary-related hospital readmissions seem to be a mix of preventable and nonpreventable diagnoses. Although pneumothorax is unpreventable, chronic obstructive pulmonary disease exacerbation may be, and pleural effusion can be, diagnosed and treated on an outpatient basis. Most of the diagnoses in the "other" category are not remedied by house calls; however, it is interesting to note that readmissions for musculoskeletal pain decreased from 2 to 0 , and for edema decreased from 1 to 0 . It is possible that PA-directed use of analgesia and diuretics during home visits may have contributed to this finding, but we are unable to prove it.

A total of 122 interventions were made over the course of 454 house calls, indicating that $27 \%$ of visits prompted an intervention. A total of 122 interventions on 275 patients suggests an interventional rate of $44 \%$; however, knowing that some patients received 2 or more interventions on the same visit, the true rate of patients requiring an intervention is lower. By far the most common intervention was medication adjustment $(90 \%)$, followed by

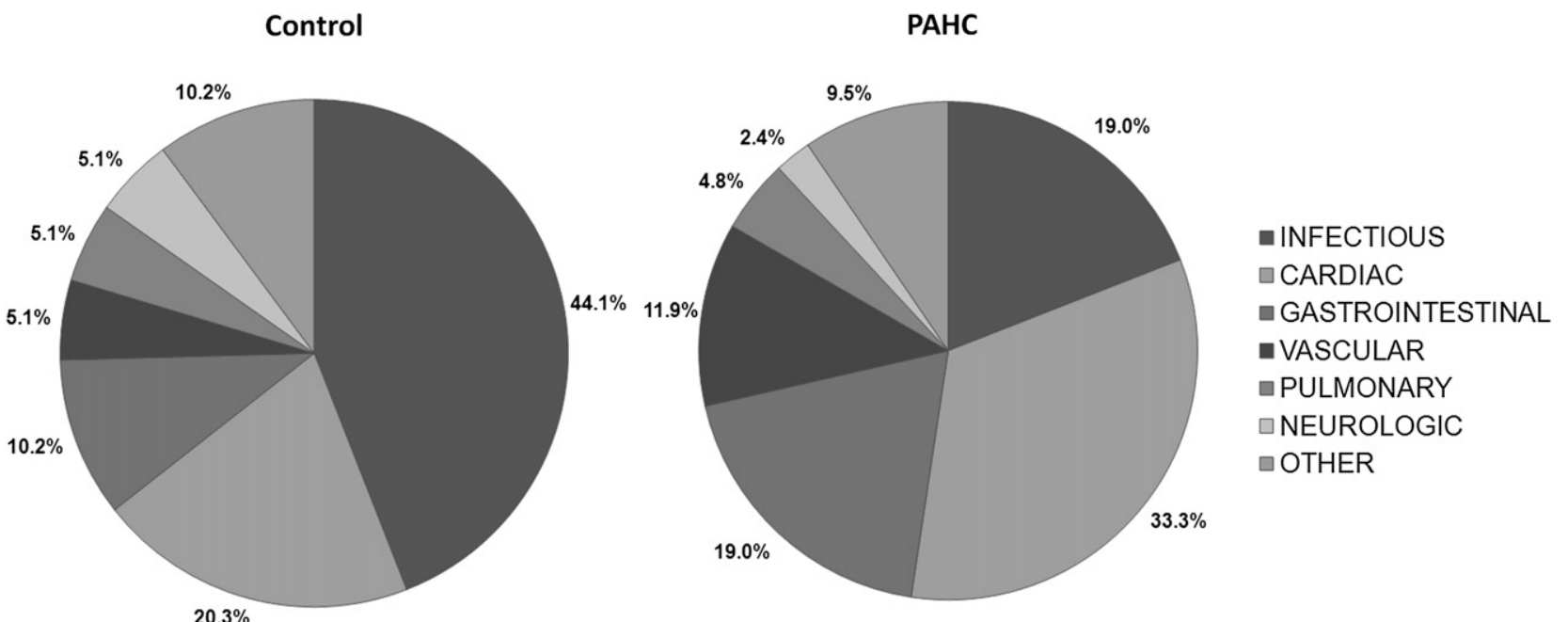

FIGURE 2. Overall readmissions in the control and physician assistant home care (PAHC) groups. 
TABLE 2. Thirty-day readmissions by diagnosis

\begin{tabular}{|c|c|c|c|}
\hline Diagnosis & $\begin{array}{l}\text { Control group } \\
(\mathbf{n}=\mathbf{5 9})\end{array}$ & $\begin{array}{l}\text { PAHC group } \\
\quad(n=42)\end{array}$ & $\begin{array}{c}P \\
\text { value }\end{array}$ \\
\hline Infectious (n, \%) & $26(44)$ & $8(19)$ & .0105 \\
\hline \multicolumn{4}{|l|}{ Wound } \\
\hline Sternal & 9 & 3 & \\
\hline Lower extremity & 9 & 3 & \\
\hline Thoracoabdominal & 0 & 1 & \\
\hline Pneumonia & 5 & 1 & \\
\hline Sepsis & 3 & 0 & \\
\hline Cardiac (n, \%) & $12(20)$ & $14(33)$ & 1692 \\
\hline Atrial dysrhythmia & 3 & 8 & \\
\hline Myocardial infarction & 2 & 3 & \\
\hline Congestive heart failure & 4 & 0 & \\
\hline Pericardial effusion & 2 & 1 & \\
\hline Syncope/near syncope & 1 & 1 & \\
\hline Cardiac arrest & 0 & 1 & \\
\hline Gastrointestinal (n, \%) & $6(10)$ & $8(19)$ & .2484 \\
\hline \multicolumn{4}{|l|}{ Bleeding } \\
\hline Upper & 2 & 5 & \\
\hline Lower & 1 & 1 & \\
\hline Cholecystitis & 1 & 1 & \\
\hline Ileus & 1 & 0 & \\
\hline Small bowel obstruction & 1 & 0 & \\
\hline Incarcerated inguinal hernia & 0 & 1 & \\
\hline Vascular $(\mathrm{n}, \%)$ & $3(5)$ & $5(12)$ & .4456 \\
\hline Deep vein thrombosis & 2 & 2 & \\
\hline Pulmonary embolus & 0 & 2 & \\
\hline Acute arterial occlusion & 0 & 1 & \\
\hline Thrombophlebitis & 1 & 0 & \\
\hline Pulmonary (n, \%) & $3(5)$ & $2(5)$ & 1.0000 \\
\hline Pleural effusion & 2 & 0 & \\
\hline Pulmonary edema & 0 & 1 & \\
\hline COPD exacerbation & 0 & 1 & \\
\hline Pneumothorax & 1 & 0 & \\
\hline Neurologic (n, \%) & $3(5)$ & $1(2)$ & .6392 \\
\hline Cerebrovascular accident & 1 & 0 & \\
\hline Transient ischemic attack & 1 & 0 & \\
\hline Anxiety & 1 & 0 & \\
\hline Confusion & 0 & 1 & \\
\hline Other $(\mathrm{n}, \%)$ & $6(10)$ & $4(10)$ & 1.0000 \\
\hline \multicolumn{4}{|l|}{ Medication related } \\
\hline Warfarin toxicity & 2 & 0 & \\
\hline Drug reaction & 0 & 1 & \\
\hline Musculoskeletal pain & 2 & 0 & \\
\hline Edema & 1 & 0 & \\
\hline Acute renal failure & 1 & 0 & \\
\hline Epistaxis & 0 & 1 & \\
\hline Chylothorax & 0 & 1 & \\
\hline $\begin{array}{l}\text { Blurry vision (secondary to } \\
\text { laser vision correction } \\
\text { procedure) }\end{array}$ & 0 & 1 & \\
\hline
\end{tabular}

Data are present as no. of patients unless otherwise stated. $P A H C$, Physician assistant home care; $C O P D$, chronic obstructive pulmonary disease.

imaging studies (venous duplex 5\% and chest radiograph $2 \%)$ and wound care $(2 \%)$. The most common home intervention, diuretic adjustment in 37 patients, correlates well with the decrease in readmissions for congestive heart failure from 4 to 0 , and edema from 1 to 0 . It is surprising to note that despite the significant decrease in readmissions for infectious diagnoses, only 15 of the 122 interventions at home specifically addressed infections (antibiotic prescription and wound care). However, 5 of the interventions for hypoglycemia were initiation or increase of medication that promoted normoglycemia and may have contributed to lowering the rate of infection-related readmissions. The very act of inquiring about blood sugar monitoring and finger stick results may have reinforced dietary and medication compliance in patients where no adjustment was indicated.

Because this was an intention-to-treat analysis, it is important to note that during the 13 months of our PAHC program, 65 patients either refused home visits or accepted but subsequently did not answer the telephone when called to schedule a time for the home visit. We did not combine the results from these patients to our analysis of the control group, realizing the inevitability of some patients refusing or failing to arrange at least 1 home visit $(19 \%$ in our experience). Nevertheless they may be considered as a control group for the purpose of discussion. Of these patients, 59 $(91 \%)$ were seen in the office in the same manner as the control group, 10 of whom $(17 \%)$ were ultimately readmitted to the hospital within 30 days of surgery. Six patients were seen neither at home nor in the office, and $1(17 \%)$ was readmitted. Again, despite the numbers being too small to be useful statistically, they are remarkably consistent with the overall readmission rate in the control group (16\%).

Of patients readmitted during the PAHC period, $18(43 \%)$ received 2 visits, $13(31 \%)$ received 1 visit, and $11(26 \%)$ received no visits. This finding is counterintuitive and difficult to explain. We may only speculate that some of the patients who refuse visits are healthier, have fewer comorbidities, and therefore deem house calls to be an unnecessary intrusion upon their daily routine. As a result, some PAHC refusers may be a self-selected group less likely to require readmission in general, regardless of postdischarge follow-up protocol.

\section{Limitations}

Only patients living in Staten Island and select neighboring counties in New Jersey were visited. Patients living beyond our visiting range were not seen. More importantly, we have no data regarding readmissions for patients living beyond Staten Island (33 in the control group [9\%] and 25 in the PAHC group [7\%]). Some of these patients may have been admitted to other hospitals without our knowledge, although typically we are notified by an admitting hospital or the patient's family.

None of the patients who were discharged to a rehabilitation unit or to a nursing home were visited by a PA. It is unknown how readmissions from those institutions would 


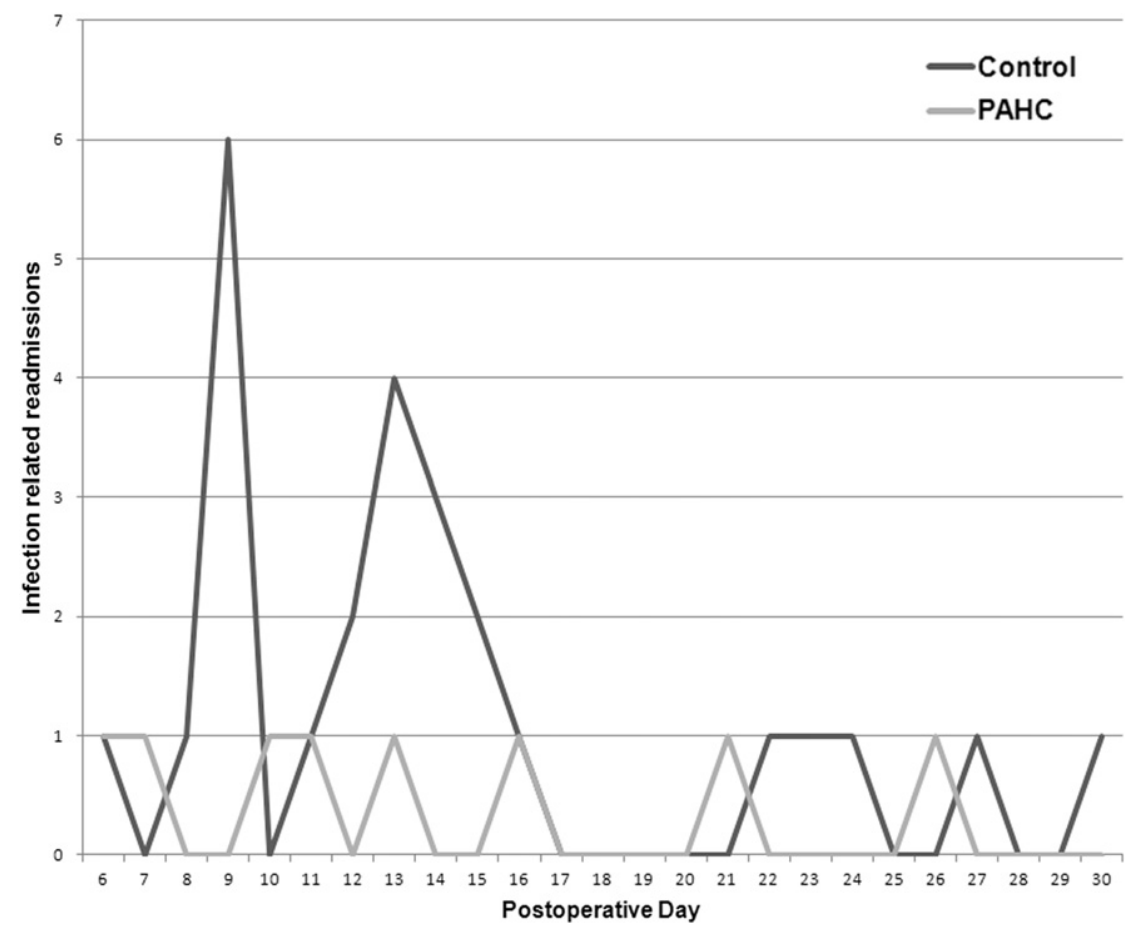

FIGURE 3. Thirty-day infection-related hospital readmissions control and physician assistant home care (PAHC) groups.

change the distribution of readmission diagnosis. Home visits were offered to every patient discharged to home; however, it is possible that those who refused house calls may introduce a selection bias. Finally, the small readmissions total is an important limitation.

\section{CONCLUSIONS}

Our PAHC program reduced the 30-day postoperative hospital readmission rate by $25 \%$ in patients who were discharged to home. By making house calls we significantly reduced hospital readmissions for infectious reasons and decreased readmissions for some cardiac, pulmonary, and neurologic diagnoses. Readmissions related to gastrointestinal and vascular diagnoses were not reduced by home visits. The most common intervention made during PAHC visits was medication adjustment, most commonly to diuretics, hypoglycemics, and antibiotics.

TABLE 3. Thirty-day hospital readmissions as a percentage of cohort

\begin{tabular}{lccr}
\hline \multicolumn{1}{c}{ Diagnosis } & $\begin{array}{c}\text { Control group } \\
(\mathbf{n}=\mathbf{3 6 1})\end{array}$ & $\begin{array}{c}\text { PAHC group } \\
(\mathbf{n}=\mathbf{3 4 0})\end{array}$ & $\boldsymbol{P}$ value \\
\hline Infectious & $26(7)$ & $8(2)$ & .0046 \\
Cardiac & $12(3)$ & $14(4)$ & .6908 \\
Gastrointestinal & $6(2)$ & $8(2)$ & .5956 \\
Vascular & $3(1)$ & $5(1)$ & .4949 \\
Pulmonary & $3(1)$ & $2(1)$ & 1.0000 \\
Neurologic & $3(1)$ & $1(0.3)$ & .6247 \\
Other & $6(2)$ & $4(1)$ & .7535 \\
\hline Da &
\end{tabular}

Data are presented as $\mathrm{n}(\%)$. PAHC, Physician assistant home care.
We would like to acknowledge the Division of Cardiothoracic Surgery's PA staff for their commitment and dedication to the home care program (Robert Carlucci, Cecilia Castor, Diane Diaz, Elissa Lebow, Nicholas Lezzo, Victoria Otterbeck, Jeff Pampinella, Linda Sakarissen, Christine Soliven, and George

TABLE 4. Interventions performed by physician assistants during home care

\begin{tabular}{lrr}
\hline Intervention type & No. & $\%$ \\
\hline Medications & 110 & 90 \\
Diuretic & 37 & 30 \\
Hypoglycemic & 15 & 12 \\
Antibiotic & 12 & 10 \\
Stool softener/laxative & 11 & 9 \\
Beta-blocker & 9 & 7 \\
Other & 26 & 21 \\
Antihypertensive & 5 & 4 \\
Inhaler & 4 & 3 \\
Analgesic & 4 & 3 \\
Anticoagulant & 4 & 3 \\
Aspirin & 2 & 2 \\
Steroid & 2 & 2 \\
Antiarrhythmic & 1 & 1 \\
Antihistamine & 1 & 1 \\
Antitussive & 1 & 1 \\
Hypnotic & 1 & 1 \\
Proton pump inhibitor & 1 & 1 \\
Wound care & 3 & 2 \\
Chest x-ray film & 3 & 2 \\
Venous duplex & 6 & 5 \\
\hline & &
\end{tabular}


TABLE 5. Medication adjustments made during physician assistant home care visits

\begin{tabular}{|c|c|c|c|c|c|}
\hline Medication & Total interventions & Initiated & Increased & Decreased & Stopped \\
\hline Furosemide & 37 & 20 & 16 & & 1 \\
\hline Metoprolol & 9 & 3 & 4 & 2 & \\
\hline Amoxicillin/clavulanate & 8 & & 8 & & \\
\hline Insulin aspart & 6 & & 1 & 5 & \\
\hline Insulin glargine & 5 & & 1 & 4 & \\
\hline Docusate & 4 & 2 & 2 & & \\
\hline Lactulose & 4 & 4 & & & \\
\hline Lisinopril & 4 & 1 & 1 & & 2 \\
\hline Ipratropium & 4 & 4 & & & \\
\hline Warfarin & 4 & 4 & & & \\
\hline Metformin & 3 & & 2 & & 1 \\
\hline Cephalexin & 2 & 2 & & & \\
\hline Laxative & 2 & 2 & & & \\
\hline Acetaminophen & 2 & 2 & & & \\
\hline Prednisone & 2 & 2 & & & \\
\hline Aspirin (81 mg) & 2 & 2 & & & \\
\hline Glipizide & 1 & 1 & & & \\
\hline Trimethoprim/sulfamethoxazole & 1 & 1 & & & \\
\hline Ciprofloxacin & 1 & 1 & & & \\
\hline Amiodarone & 1 & & 1 & & \\
\hline Senna & 1 & 1 & & & \\
\hline Oxycodone/acetaminophen & 1 & 1 & & & \\
\hline Hydrocodone/acetaminophen & 1 & 1 & & & \\
\hline Amlodipine & 1 & & & & 1 \\
\hline Diphenhydramine & 1 & 1 & & & \\
\hline Guaifenesin & 1 & 1 & & & \\
\hline Esomeprazole & 1 & 1 & & & \\
\hline Zolpidem & 1 & & 1 & & \\
\hline
\end{tabular}

Varghese). In addition, we thank the volunteers who assisted with data collection (Igor Borodyansky, Alexander Calamia, Kathryn Calamia, Anahita Ghavami, Shahrukh Khan, Sulayman Mughal, Anthony Nagib, and Natasha Pover). Special thanks to Drs Robert Silverman, Deliana Peykova and Kourosh Asgarian, Ann Eichorn, and PA Renee Aboushi for their help in bringing this project together.

\section{References}

1. Hannan EL, Zhong Y, Lahey SJ, Culliford AT, Gold JP, Smith CR, et al. 30-day readmissions after coronary artery bypass graft surgery in New York State. JACC Cardiovasc Interv. 2011;4:569-76.

2. Lazar HL, Fitzgerald CA, Ahmad T, Bao Y, Colton T, Shapira OM, et al. Early discharge after coronary artery bypass graft surgery: are patients really going home earlier? J Thorac Cardiovasc Surg. 2001;121:943-50.

3. Pennsylvania Health Care Cost Containment Council. Hospital readmissions following coronary artery bypass surgery. Harrisburg: Pennsylvania Health Care Cost Containment Council; 2001.

4. Rankin SH, Butzlaff A, Carroll DL, Reedy I. FAMISHED for support: recovering elders after cardiac events. Clin Nurse Spec. 2005;19:142-9.

5. Vaccarino V, Lin ZQ, Kasl SV, Mattera JA, Roumanis SA, Abramson JL, et al. Gender differences in recovery after coronary artery bypass surgery. $J$ Am Coll Cardiol. 2003;41:307-14.

6. Barnason S, Zimmerman L, Nieveen J, Schmaderer M, Carranza B, Reilly S. Impact of a home communication intervention for coronary artery bypass graft patients with ischemic heart failure on self-efficacy, coronary disease risk factor modification, and functioning. Heart Lung. 2003;32:147-58.

7. Buls $P$. The effects of home visits on anxiety levels of the client with a coronary artery bypass graft and of the family. Home Healthc Nurse. 1995;13:22-9.
8. Lie I, Arnesen H, Sandvik L, Hamilton G, Bunch EH. Health-related quality of life after coronary artery bypass grafting. The impact of a randomised controlled home-based intervention program. Qual Life Res. 2009;18:201-7.

9. Lie I, Arnesen H, Sandvik L, Hamilton G, Bunch EH. Effects of a home-based intervention program on anxiety and depression 6 months after coronary artery bypass grafting: a randomized controlled trial. J Psychosom Res. 2007;62: 411-8.

10. Hartford K, Wong C, Zakaria D. Randomized controlled trial of a telephone intervention by nurses to provide information and support to patients and their partners after elective coronary artery bypass graft surgery: effects of anxiety. Heart Lung. 2002;31:199-206.

11. Shapiro K, Patel S, Steinberg S, Ferzli G. Postoperative home visits? Curr Surg 2003;60:612-4.

12. Huisman-de Waal G, van Achterberg T, Jansen J, Wanten G, Schoonhoven L. 'Hightech' home care: overview of professional care in patients on home parenteral nutrition and implications for nursing care. J Clin Nurs. 2011;20:2125-34.

13. Fabacher D, Josephson K, Pietruszka F, Linderborn K, Morley JE, Rubenstein LZ. An in-home preventive assessment program for independent older adults: a randomized controlled trial. J Am Geriatr Soc. 1994;42:630-8.

14. Brennan PF, Moore SM, Bjornsdottir G, Jones J, Visovsky C, Rogers M. HeartCare: an Internet-based information and support system for patient home recovery after coronary artery bypass graft (CABG) surgery. $J$ Adv Nurs. 2001;35: 699-708.

15. Barnason S, Zimmerman L, Nieveen J, Hertzog M. Impact of a telehealth intervention to augment home health care on functional and recovery outcomes of elderly patients undergoing coronary artery bypass grafting. Heart Lung. 2006;35:225-33.

16. Hopp F, Woodbridge P, Subramanian U, Copeland L, Smith D, Lowery J. Outcomes associated with a home care telehealth intervention. Telemed $J$ E Health. 2006;12:297-307.

17. Beckie T. A supportive-educative telephone program: impact on knowledge and anxiety after coronary artery bypass graft surgery. Heart Lung. 1989;18:46-55. 


\section{Discussion}

Dr Anthony R. Furnary (Portland, Ore). John, you have presented a very interesting concept and a nice piece of work. I have a few questions for you and I want to be clear. The reduction in admissions was due to a reduction in infection, so the overall group was carried by the reduction in infection?

Dr Nabagiez. Right.

Dr Furnary. In the interventions you describe there were only 5 patients who received antibiotics, so it seems to me to be a little discordant. How does a home visit and maybe prescription of antibiotic medications reduce overall admission rates?

Dr Nabagiez. I had the same question. There were a couple instances of wound care. There may have been more that were not documented on the home care sheet, perhaps prescriptions that were not documented. For example, sometimes a physician assistant (PA) will look at a wound and say, "It does not look so bad, call us if you have a fever in the next 24 hours," and the patient will call the office and get a prescription. That office encounter would not necessarily be tracked on the sheet. Additionally, adjustments of medications for hypoglycemia-indeed merely inquiring about compliance with medications for hypoglycemica-might well have played a role. I think that is responsible for part of it. Also, a lot of patients are concerned about their wound and visit an emergency department. As a result, unfortunately, we have some inappropriate admissions. Admissions not based on that wound itself, but just based on the nervousness of the emergency department physician. I think a PA looking at a wound and saying, "This looks okay," prevents those sort of inappropriate readmissions.

Dr Furnary. I think this is a really important point because reduction of inappropriate admissions is probably one of the key factors going on here.

The second question I have concerns the PA visits: They happened on day 2 and day 5. When I look at your control groupand I imagine the same would be true if we looked at those who refused visits - there was a spike of readmissions during the 11- to 14-day period. With that in mind-there were also readmissions in your visit group at $8,9,10,15$, and 18 days — do you think another visit at say 11 or 12 days might be helpful?

Dr Nabagiez. That is a great question. Strangely, even though our PAs only made 2 visits, the effect of seeing patients during the first week seemed to carry through to the second week-at least for infection purposes. I think additional visits may help more in cardiac category patients, who can get into trouble in more different ways. It would be interesting to see if additional visits would make a difference.

Dr Furnary. Exactly. Another visit might help prevent readmissions for congestive heart failure, pulmonary edema, and things like that.

Let's talk about the people who refused to be visited. Do you have any sense as to why they refused a visit? Most people love to be seen by caregivers. Why not put those refusal patients into the control group? They are sort of not-historical controls and they would have added nicely.

Dr Nabagiez. I chose to not put them in with the control group because in every sample you are always going to have refusersyou are never going to get $100 \%$ to agree to a visit. I did not want to make it look like our readmission rate was better than it was.
As to why they refused, I do not know. I never actually asked a patient. Some patients - maybe the younger, healthier ones-believed it was unnecessary. Some patients just want to get on with their lives, get back to work. I do not have a good answer for that.

Dr Furnary. All right. Last question: What do your PAs think about this? Who pays for the gas and who pays the PA for their time?

Dr Nabagiez. When conducting home visits was first imposed on the PAs they absolutely hated it. Over the years they have grown to detest it moderately, so we have come a long way. Some PAs are less resistant to it than others and those do it more often. But it works, and they see the results. The PAs are hospital employees, so the visits are included as part of their work schedule for that day. They receive $\$ 0.55 /$ mile reimbursement for travel expenses.

Dr J. W. Randolph Bolton (Fresno, Calif). A number of years back we started having our nurse practitioners and PAs call patients the day after they were discharged. I got a lot fewer calls after that.

I have a couple of questions. First, when is your routine followup with the patients in your clinic? Second, why did you choose days 2 and 5? Third, rather than visits do you think a phone call and a return to clinic if appropriate would be a better-less expensive-way of going about this?

Dr Nabagiez. Great questions. I originally had the same thought; why are we going to their houses, why not just have them come to the office more frequently? To be honest, I think that would work just as well. However, there probably would be less patient compliance. I do not know that patients would be willing to come so frequently. Of course, some would show up every day if you asked them but some might not, so it certainly is a valid question.

Dr Bolton. How did you choose days 2 and 5, and when was your routine return follow-up?

Dr Nabagiez. Two and 5 were chosen by the parent institution. I did not have a say in that and I do not know how they came up with it. But it seems to work. Our routine follow-up before the home visits were implemented was basically to see them in the office during postdischarge weeks 2 and 4 and then additional visits if necessary.

Dr Scott Millikan (Billings, Mont). The holy grail of health care cost reduction in this country, as you have touched on, is decreasing hospital readmissions. Has your institution embarked on any financial analysis of your cohorts and can you share any information?

Dr Nabagiez. I wanted to pursue such an analysis, but I also did not want to muddy the waters. So I stuck to just the clinical aspect for this report. I have not run the numbers. I am going to do that with some administrators from the hospital who understand that whole process better than I do. I can tell you-my knowledge of this area is very limited - that there is a concept called transitional loss that involves the diagnosis-related group that you are paid. If you send a patient home early, rather than be rewarded, a fraction of the money goes to the visiting nurse team. So you can save that. And of course the cost of a readmission is saved, but I am sure the total, cumulatively, would be tremendous. I am going to work on that, too.

Speaker. What is the volume of discharges per year, how many nurse practitioners cover those patients, and what was the geographic range that you sent them out to? 
Dr Nabagiez. The geographic range was Staten Island itself. It is a population of about 500,000 . We did conduct some visits to some neighboring counties in New Jersey, but, you are right, some patients lived outside those areas and they did not get home visit follow-up. That was true of both groups-the control and the home visit.

The number of discharges per year for this category of patients (discharged to home) is around 350.

There are several visiting nurse services that we used to use exclusively, but now we just use this.

Speaker. How many nurse practitioners is that?

Dr Nabagiez. We do not have nurse practitioners in our practice.
Speaker. How many PAs?

Dr Nabagiez. We have about 8 to 10 .

Speaker. I have a question about length of stay versus readmission. Was there any correlation between length of stay and readmission? That is, are patients with a shorter hospital length of stay more likely to be readmitted? If a patient has a 29-day length of stay, the chance of him or her being readmitted at 30 days is almost zero. Any correlation?

Dr Nabagiez. I did not look into that. It is certainly worthy of investigation. As far as the really prolonged admissions, we did not have those. Typically those patients will wind up in a rehab facility or a nursing home and patients in that situation were excluded from this study.

\section{APPENDIX 1. Physician Assistant Home Care Form/Checklist}

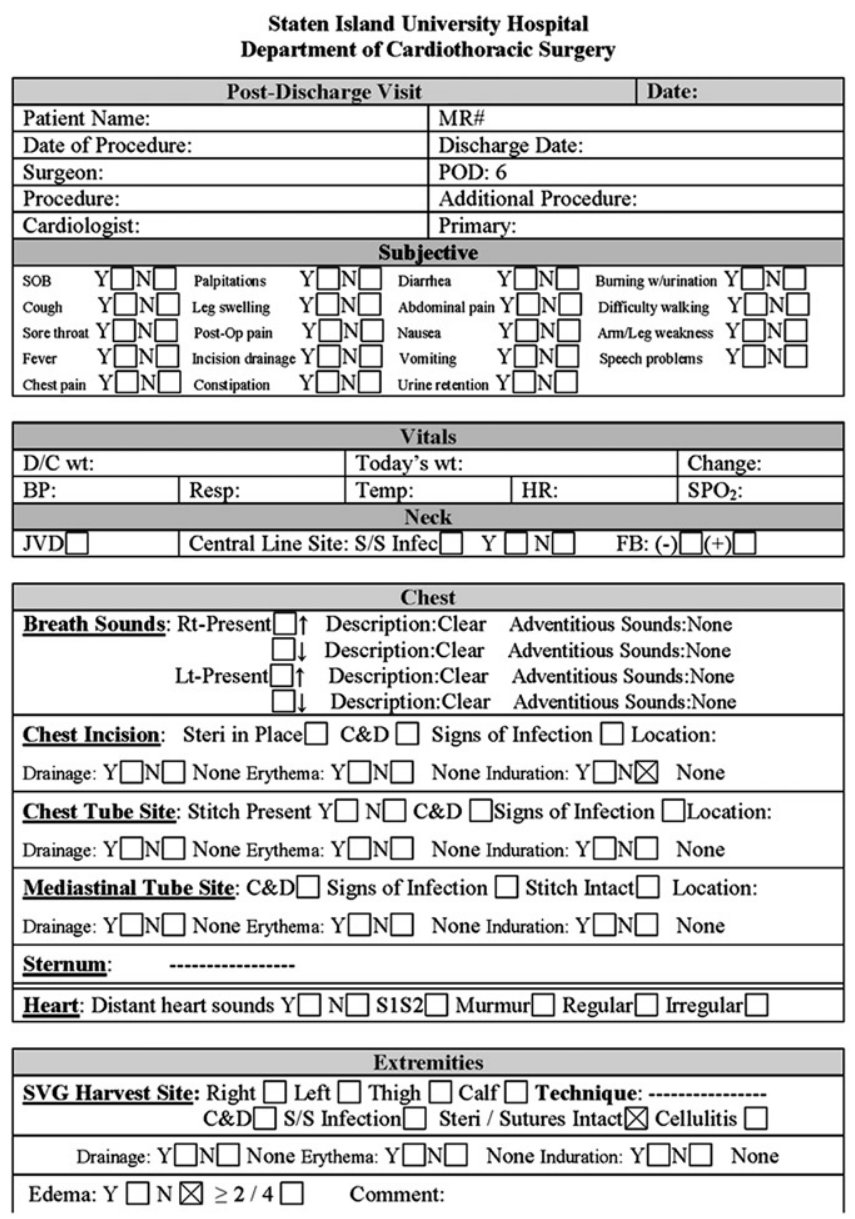

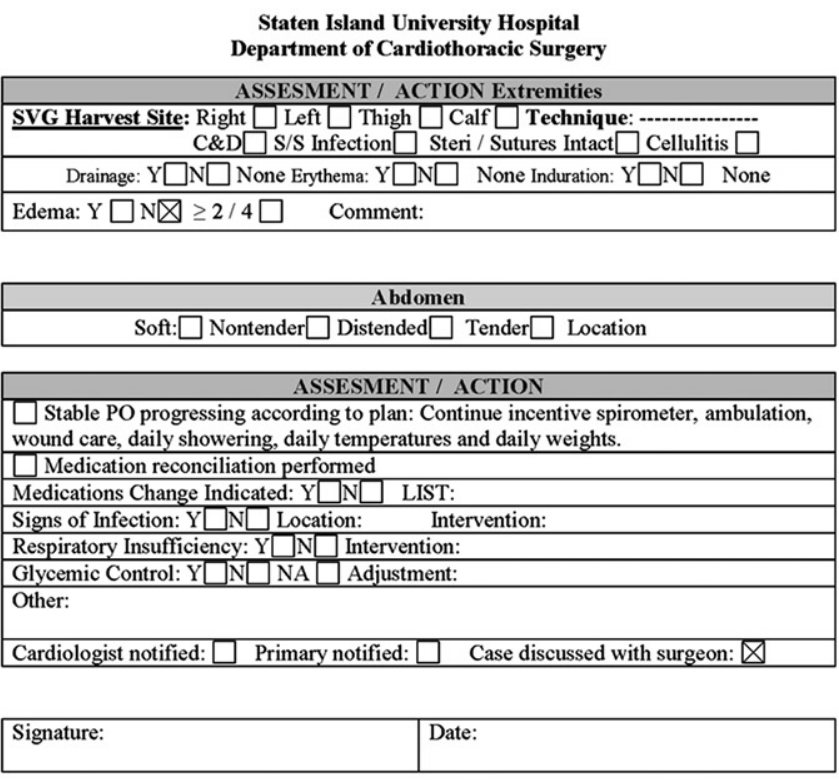

